\title{
Segregation in a sexually dimorphic mammal: a mixed-effects modelling analysis of diving behaviour in southern elephant seals
}

\author{
Trevor McIntyre ${ }^{1 *}$, Cheryl A. Tosh ${ }^{1}$, Joachim Plötz ${ }^{2}$, Horst Bornemann ${ }^{2}$, \\ Marthán N. Bester ${ }^{1}$ \\ ${ }^{1}$ Mammal Research Institute, Department of Zoology and Entomology, University of Pretoria, Pretoria 0002, South Africa \\ ${ }^{2}$ Alfred Wegener Institute for Polar and Marine Research, PO Box 120161, 27515 Bremerhaven, Germany
}

\begin{abstract}
Sexual segregation in habitat use occurs in a number of animal species, including southern elephant seals, where differences in migration localities and dive behaviour between sexes have been recorded. Due to the extreme sexual size dimorphism exhibited by southern elephant seals, it is unclear whether observed differences in dive behaviour are due to increased physiological capacity of males, compared to females, or differences in activity budgets and foraging behaviour. Here we use a mixed-effects modelling approach to investigate the effects of sex, size, age and individual variation on a number of dive parameters measured on southern elephant seals from Marion Island. Although individual variation accounted for substantial portions of total model variance for many response variables, differences in maximum and targeted dive depths were always influenced by sex, and only partly by body length. Conversely, dive durations were always influenced by body length, while sex was not identified as a significant influence. These results support hypotheses that physiological capability associated with body size is a limiting factor on dive durations. However, differences in vertical depth use appear to be the result of differences in forage selection between sexes, rather than a by-product of the size dimorphism displayed by this species. This provides further support for resource partitioning and possible avoidance of inter-sexual competition in southern elephant seals.
\end{abstract}

KEY WORDS: Sexual segregation · Sexual dimorphism · Dive behaviour - Southern elephant seals · Linear mixed-effects models · Mirounga leonina

\section{INTRODUCTION}

Sexual segregation has been defined as the separation of members of a species, such that sexes live apart, either singly or as single-sex groups (Wearmouth \& Sims 2008). It is a phenomenon present in reptiles (Ford \& Hampton 2009), fish (Mucientes et al. 2009), birds (González-Solís et al. 2008, Morales et al. 2008, Palacin et al. 2009) and mammals. In mammals, sexual segregation has been studied mostly in terrestrial species, particularly ungulates and other group-living mammals, where it appears to be very common (MacFarlane \& Coulson 2007, Ciuti \& Apollonio 2008, Hay et al. 2008, Li \& Jiang 2008, Shannon et al. 2008). It is less well documented in marine mammals, though it appears to play an important role for various cetacean species, notably for species that live in social groups (Whitehead \& Weilgart 2000, Martin \& da Silva 2004). Recent advances in satellite-tracking devices for marine species have led to new understandings of the pelagic phases of pinniped life cycles across the globe. As a result, sexual segregation in migration patterns and depths utilised has increasingly been reported for a number of seal species (Slip et al. 1994, Page et al. 2005, Wolf et al. 2005, Breed et al. 2006, Staniland \& Robinson 2008). 
Mechanisms presented to explain such difference in behaviour between sexes include (1) predator avoidance, (2) forage selection, (3) differences in activity budgets, (4) thermal niche-fecundity in ectotherms, and (5) social factors (Ruckstuhl 2007, Staniland \& Robinson 2008, Wearmouth \& Sims 2008). Notably, many of these hypotheses are associated with sexual size dimorphism and predict positive correlations of sexual segregation with sexual size dimorphism.

Southern elephant seals are extremely sexually dimorphic, with males sometimes being up to 10 times larger than females (Le Boeuf \& Laws 1994). Adult animals haul out at breeding colony sites twice during a year-once during the breeding period (austral spring) and once for the annual moult (austral mid to late summer). Segregation in forage locations between the sexes in southern elephant seals have been reported for animals from various localities (Slip et al. 1994, Campagna et al. 1995, McConnell \& Fedak 1996, Campagna et al. 1999, Bornemann et al. 2000, Tosh et al. 2009). Similarly, a number of studies demonstrate segregation in dive behaviour, with females foraging mostly pelagically while males tend to either forage benthically or show greater variation in forage strategy, often employing both pelagic and benthic strategies (Hindell et al. 1991, McConnell et al. 1992, Campagna et al. 1995, Jonker 1997, Malherbe 1998, Campagna et al. 1999, Field et al. 2005b).

Such differences in forage locations and dive behaviour are thought to be associated with sex-specific foraging strategies in this species, with males reportedly adopting more risky foraging strategies in order to maximise early growth (Lewis et al. 2006, Field et al. 2007a). Such segregation has largely been attributed to inter-sexual competition avoidance in this species (Field et al. 2005b, Lewis et al. 2006). While such investigations reported clear differences in foraging strategies between males and females, no attempts were made to quantify the effects of body size differences between sexes. This is important since the extreme sexual dimorphism of this species is likely to influence dive parameters and cloud the potential influence of sex versus body size on the dive behaviour of elephant seals.

Here we investigate sexual differences in dive behaviour of southern elephant seals from Marion Island. Our aims were specifically to determine if differences in dive parameters between sexes were a result of inherent sex-related traits or merely a byproduct of size differences between sexes. Because of the unbalanced nature of available data, we utilised a mixed-effects modelling approach to elucidate the effects of sex, standard length and age on the depth utilisation of elephant seals.

\section{MATERIALS AND METHODS}

Satellite-tag deployments. A total of 57 satellite-relay data loggers (Sea Mammal Research Unit, University of St. Andrews, Scotland) were deployed on southern elephant seals of known age and sex hauled out at Marion Island $\left(46^{\circ} 54^{\prime} \mathrm{S}, 37^{\circ} 45^{\prime} \mathrm{E}\right)$. Deployments were made on known individuals, born and flipper-tagged on the island as part of a long-term mark-recapture investigation (Bester 1988, de Bruyn et al. 2008). Two types of satellite-relay data logger (SRDL) were used in this investigation: 33 SRDL Series 9000 and 24 SRDL-CTD devices. Devices were glued onto the cranial pelage of immobilised animals (for further details see Tosh et al. [2009]). All SRDLs were programmed to measure pressure every $4 \mathrm{~s}$ during each dive of the animal. Only dives deeper than $6 \mathrm{~m}$ were recorded. Detailed dive data were compressed onboard the instruments, prior to transmission, using a broken-stick algorithm to provide 4 dive points reflecting the greatest inflections, as well as the maximum depth reached within the dive (Fedak et al. 2001, Boehme et al. 2009). This information was relayed via service Argos (Argos 1996), along with environmental data (SRDL Series 9000 devices recorded temperature profiles, while SRDL-CTD devices recorded temperature and conductivity profiles), and position estimates calculated from Doppler shift measurements in successive uplinks. All dive and environmental meta-data are available in open access via the PANGAEA information system (www.pangaea.de).

For the purposes of this investigation we included data obtained only from animals for which deployments were made prior to post-moult migrations (as opposed to post-breeding migrations). Also, only tracks obtained from animals with measured standard length data (with the seal in ventral recumbency) and known ages at the time of deployment were included. Few mass measurements were available for the study animals, precluding the inclusion of mass as an indication of body size. We further removed data obtained from the largest males and smallest females of known lengths (males: $\mathrm{n}=2$; females: $\mathrm{n}=3$ ) in order to ensure substantial overlap in standard lengths between sexes and remove a possible confounding effect between sex and standard length (see Results). This resulted in data being retained from 20 (12 females and 8 males; Table 1) tracks for this study.

Filtered tracks (see Tosh et al. 2009) were plotted in Arcview 3.3 (ESRI 1998). Space use and the extent of movements were calculated using Animal Movement Analyst (Hoodge \& Eichenlaub 1997). Kernel density estimators based on all locations further than $200 \mathrm{~km}$ from Marion Island were calculated in order to determine space use probabilities (95\% and 50\%) for females and males separately. Minimum convex poly- 
Table 1. Dive characteristics of selected southern elephant seal tracks used in this investigation. Only dives with a positive residual value resulting from the regression of bottom time as a function of maximum dive depth and dive duration (indicating increased forage effort) were included. Stdl = standard length $(\mathrm{cm}) ; \mathrm{DD}=$ dive duration $(\mathrm{min}) ; \mathrm{MD}=$ maximum depth $(\mathrm{m}) ; \mathrm{ED}=$ exploited dive depth $(\mathrm{m})$. Values arepresented as means $( \pm \mathrm{SD})$ of individual seal averaged values

\begin{tabular}{|c|c|c|c|c|c|c|c|c|c|c|c|}
\hline Animal & Track & Sex & Year & Age (yr) & Stdl & $\mathrm{DD}_{\mathrm{DAY}}$ & $\mathrm{DD}_{\text {NIGHT }}$ & $\mathrm{MD}_{\mathrm{DAY}}$ & $\mathrm{MD}_{\text {NIGHT }}$ & $\mathrm{ED}_{\mathrm{DAY}}$ & $\mathrm{ED}_{\mathrm{NIGHT}}$ \\
\hline BB081 & BB081 & $\mathrm{m}$ & 2008 & 5.3 & 252 & $36 \pm 12$ & $29 \pm 10$ & $732 \pm 149$ & $465 \pm 219$ & $687 \pm 142$ & $439 \pm 197$ \\
\hline BB128 & BB128 & $\mathrm{m}$ & 2008 & 5.3 & 293 & $38 \pm 13$ & $26 \pm 10$ & $743 \pm 148$ & $426 \pm 166$ & $723 \pm 155$ & $375 \pm 147$ \\
\hline BB253 & BB253 & $\mathrm{m}$ & 2005 & 2.6 & 214 & $24 \pm 5$ & $19 \pm 4$ & $563 \pm 90$ & $457 \pm 164$ & $530 \pm 90$ & $406 \pm 153$ \\
\hline BB263 & BB263 & $\mathrm{m}$ & 2006 & 3.7 & 231 & $30 \pm 5$ & $22 \pm 6$ & $684 \pm 130$ & $501 \pm 175$ & $632 \pm 128$ & $445 \pm 176$ \\
\hline GG335 & GG335_2 & $\mathrm{f}$ & 2008 & 8.3 & 235 & $34 \pm 12$ & $30 \pm 9$ & $556 \pm 150$ & $422 \pm 120$ & $518 \pm 146$ & $388 \pm 118$ \\
\hline OO021 & OO021_2 & $\mathrm{f}$ & 2008 & 6.3 & 225 & $34 \pm 8$ & $25 \pm 6$ & $546 \pm 102$ & $394 \pm 92$ & $520 \pm 100$ & $355 \pm 91$ \\
\hline OO052 & OO052_1 & $\mathrm{m}$ & 2006 & 4.6 & 280 & $43 \pm 13$ & $32 \pm 11$ & $722 \pm 181$ & $572 \pm 261$ & $682 \pm 183$ & $526 \pm 258$ \\
\hline OO086 & OO086 & $\mathrm{m}$ & 2005 & 3.5 & 260 & $33 \pm 10$ & $23 \pm 8$ & $682 \pm 194$ & $498 \pm 164$ & $615 \pm 182$ & $428 \pm 155$ \\
\hline OO418 & OO418 & f & 2008 & 6.4 & 230 & $28 \pm 8$ & $21 \pm 6$ & $550 \pm 154$ & $367 \pm 164$ & $504 \pm 145$ & $327 \pm 160$ \\
\hline $\mathrm{PO} 043$ & PO043_1 & $\mathrm{f}$ & 2007 & 8.3 & 254 & $18 \pm 15$ & $24 \pm 23$ & $310 \pm 142$ & $332 \pm 142$ & $265 \pm 142$ & $291 \pm 146$ \\
\hline RR009 & RR009 & $\mathrm{m}$ & 2008 & 3.2 & 210 & $16 \pm 14$ & $20 \pm 19$ & $310 \pm 140$ & $405 \pm 203$ & $270 \pm 132$ & $360 \pm 207$ \\
\hline WW058 & WW058 & f & 2008 & 7.3 & 244 & $31 \pm 8$ & $24 \pm 7$ & $555 \pm 178$ & $372 \pm 187$ & $510 \pm 169$ & $330 \pm 178$ \\
\hline WW061 & WW061 & $\mathrm{f}$ & 2008 & 7.3 & 233 & $33 \pm 6$ & $25 \pm 5$ & $592 \pm 109$ & $407 \pm 128$ & $550 \pm 106$ & $361 \pm 123$ \\
\hline YY150 & YY150 & $\mathrm{m}$ & 2008 & 4.2 & 265 & $36 \pm 14$ & $28 \pm 9$ & $638 \pm 200$ & $423 \pm 179$ & $599 \pm 200$ & $373 \pm 166$ \\
\hline \multirow[t]{3}{*}{ YY189 } & YY189_1 & $\mathrm{f}$ & 2006 & 2.5 & 222 & $35 \pm 6$ & $23 \pm 5$ & $625 \pm 98$ & $427 \pm 108$ & $579 \pm 97$ & $383 \pm 106$ \\
\hline & YY189_2a & $\mathrm{f}$ & 2007 & 3.3 & 224 & $28 \pm 9$ & $20 \pm 5$ & $563 \pm 102$ & $432 \pm 98$ & $524 \pm 100$ & $390 \pm 100$ \\
\hline & YY189_3a & $\mathrm{f}$ & 2008 & 4.3 & 242 & $30 \pm 10$ & $24 \pm 7$ & $522 \pm 116$ & $372 \pm 97$ & $491 \pm 119$ & $334 \pm 96$ \\
\hline YY193 & YY193_2 & $\mathrm{f}$ & 2008 & 4.3 & 224 & $31 \pm 10$ & $24 \pm 9$ & $502 \pm 115$ & $286 \pm 128$ & $467 \pm 114$ & $254 \pm 125$ \\
\hline YY264 & YY264_2 & $\mathrm{f}$ & 2008 & 4.4 & 236 & $32 \pm 10$ & $23 \pm 7$ & $497 \pm 133$ & $297 \pm 125$ & $467 \pm 132$ & $260 \pm 123$ \\
\hline YY348 & YY348_2 & $\mathrm{f}$ & 2008 & 4.4 & 227 & $35 \pm 10$ & $22 \pm 6$ & $571 \pm 173$ & $370 \pm 185$ & $537 \pm 166$ & $329 \pm 176$ \\
\hline
\end{tabular}

gons (MCPs) were drawn to determine the maximum extent of movements for both sexes.

Dive analyses. We removed all incomplete (containing missing values) or unrealistic (containing sequential time values that are not chronological) dive sequences prior to analysis. Due to the compressed format in which dive data are received, estimating times spent by animals within various depth layers is problematic. We therefore used a simple interpolating algorithm, assuming constant swim speeds and directions between transmitted dive points, to calculate estimated times spent within various depth layers $(100 \mathrm{~m}$ increments from the surface to $1000 \mathrm{~m}$, thereafter 1000-1250 m, 1250-1500 m, 1500-2000 m, and $>2000 \mathrm{~m}$ ) for each transmitted dive profile (see McIntyre et al. 2010 for further details). We then identified the mid-depth value of each depth layer in which an animal spent the most time during any particular dive (e.g. if the seal spent the largest amount of time in the 0 to $100 \mathrm{~m}$ depth layer, then $50 \mathrm{~m}$ ). This was referred to here as the exploited depth.

To account for variation in dive behaviour associated with differing activity (e.g. foraging, travelling or resting) we identified individual dives with longer-thanaverage bottom times for each track (Bailleul et al. 2008). Accordingly, we calculated bottom time as the time spent by an animal at depths exceeding $80 \%$ of the maximum depth point for that dive (Lesage et al. 1999, Schreer et al. 2001, Burns et al. 2008). We then used linear regressions to calculate average bottom times for dives with given dive durations and maximum dive depths (Bailleul et al. 2008). The residual values obtained from these regressions then identified individual dives as being characterised by longer- and shorter-than-average bottom times. Dives with positive residuals (indicating longer-than-average bottom times) were assumed to suggest increased foraging effort and were retained for further analysis.

Diel variation in dive behaviour has been documented for a number of seal species, including southern elephant seals (Jonker \& Bester 1994, Campagna et al. 1995, Bennet et al. 2001, Bajzak et al. 2009). We therefore classified each dive according to day-stage (day, night, sunrise, sunset), accounting for spatial position and season. Local times for each dive were calculated according to the associated longitude values of each dive and the appropriate standard time zone (based on UTC). Seasonal local times of sunrise and sunset for 2009 (by latitude) were obtained from the National Oceanic and Atmospheric Administration (NOAA) (www.srrb.noaa.gov/highlights/sunrise/sunrise. html). Local-time hour values of dives, season and local times of sunrise/sunset were then used to classify the day-stages of individual dives.

To account for the potential influences of sea ice on individual dive behaviour, we further removed all dive data collected at latitudes higher than $60^{\circ} \mathrm{S}$. Data used in the models were therefore restricted to dives with positive bottom dive residuals, completed at latitudes lower than $60^{\circ} \mathrm{S}$. 

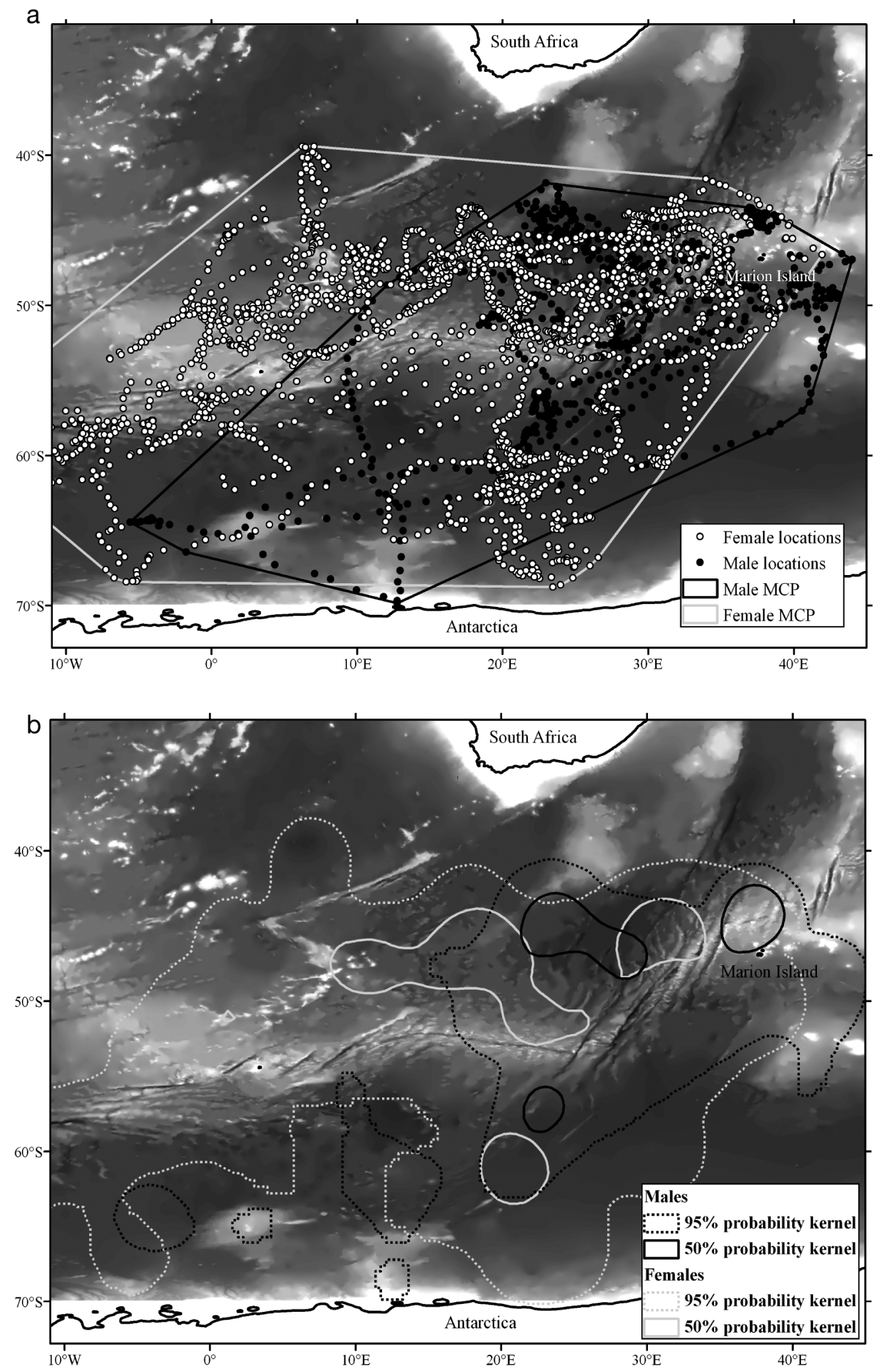

Fig. 1. (a) Daily averaged dive locations of the 20 animals (8 males; 12 females) tracked in this study. Minimum convex polygons (MCPs) of their track data are indicated. Background shading indicates the underlying bathymetry (dark shading = deeper water; light shading $=$ shallower water) $(\mathrm{b})$ Kernel density estimates of the 20 (8 males; 12 females) southern elephant seal tracks included in this investigation 
Statistical analyses and model selection. All parameters presented were summarised to daily mean values per track. This was done to smooth out potential biases associated with unsuccessful transmissions of dive profiles (Vincent et al. 2002, Boehme et al. 2009), and potential biases in the likelihood of successful transmissions associated with geographic positions and the orbit of Argos satellites (Argos 1996). Daily mean values further allowed for modelling of temporal autocorrelation, using functions that were computationally too intensive to use on raw data (see below).

Maximum dive depths ( $\left.\mathrm{MD}_{\mathrm{DAY}} / \mathrm{MD}_{\mathrm{NIGHT}}\right)$, dive durations ( $\left.\mathrm{DD}_{\mathrm{DAY}} / \mathrm{DD}_{\mathrm{NIGHT}}\right)$ and exploited depths $\left(\mathrm{ED}_{\mathrm{DAY}} /\right.$ ED $D_{\text {NIGHT }}$ ) were compared with linear mixed-effects models (LMEs). Three covariates were considered in the models: sex, start age (age of animals at the time of deployment) and standard length. These were included in the models as fixed effects, and individual tracks as a random effect. Restricted maximum likelihood (REML) estimation was employed in all model fits, following Bolker et al. (2009).

Autocorrelation plots revealed significant temporal autocorrelation evident in all models. We therefore modelled temporal autocorrelation dependencies, by including autoregressive functions (Pinheiro \& Bates 2004, Crawley 2007). Final model covariates were chosen using backwards selection, starting with the 3 covariates models. We used second order Akaike's information criterion (AIC) statistics for small sample sizes (Burnham \& Anderson 2002) to govern initial model selection, along with various plot types to assess model fits (Pinheiro \& Bates 2004). Hypothesis tests ( $F$ tests) were carried out on the final models to distinguish significance of the various fixed effects (Bolker et al. 2009). Variance components analyses were also carried out on the final mixed-effects models to estimate the variation explained by random effects (individual) (Börger et al. 2006, Crawley 2007, Bunnefeld et al. 2009).

Models were run using $\mathrm{R}$ version 2.7.1 (R Development Core Team 2008). The significance level for all tests was set at $\mathrm{p} \leq 0.05$.

\section{RESULTS}

Male and female animals in our study travelled in similar directions from Marion Island, predominantly to the west and southwest (Fig. 1a). MCPs indicated substantial overlap in total areas utilised between sexes. Fifty percent kernel density estimates indicated less overlap between the sexes, though these areas were in similar regions (Fig. 1b). Males appeared to concentrate their movements closer to Marion Island than did females. Bottom depth estimates (Smith \&
Sandwell 1997) of the individual dive locations indicated substantial overlap in bottom depths between sexes, though males tended to dive in areas with slightly shallower water depths than females (males: $3523 \pm 1622 \mathrm{~m}$; females: $4399 \pm 851 \mathrm{~m}$ ) (Fig. 2).

The 20 tracks resulted in 99302 dives that were successfully transmitted. The filtering process removed 5090 dives, resulting in 94212 dives remaining for analyses. Of these, 72794 dives had calculated bottom times greater than 0 and were used to calculate bottom time residuals. After removal of dives located at latitudes higher than $60^{\circ} \mathrm{S}$, daily averaging resulted in 2810 'dive days' and 2924 'dive nights'.

Start age was not significantly correlated with standard length (Pearson: $r=0.24$, df $=18, p=0.31$ ), and standard length was not significantly correlated with sex (Pearson: $r=0.41, \mathrm{df}=18, \mathrm{p}=0.07$ ) in our study animals. While backwards selection was employed, models were always run with all possible combinations of fixed variables. Models including each of the fixed variables provided the best fit to the data set for each of the dive parameters in our study (Table 2).

\section{Maximum dive depths}

Males dived to deeper mean maximum dive depths than females, and both sexes dived to deeper mean depths during daytime, when compared to night-time dives $\left(\right.$ Males $_{\mathrm{DAY}}=663.6 \pm 186 \mathrm{~m} ;$ Males $_{\mathrm{NIGHT}}=466.8 \pm$ $196.58 \mathrm{~m}_{\text {; }}$ Females $_{\mathrm{DAY}}=548.5 \pm 138 \mathrm{~m}$; Females $_{\mathrm{NIGHT}}=$ $382.3 \pm 140.8 \mathrm{~m})$. Males displayed more variation in maximum dive depths than females (ANOVA ${ }_{\mathrm{DAY}}$ : $F_{1,17230}=2100.2, \mathrm{p}<0.001 ;$ ANOVA $_{\mathrm{NIGHT}}: F_{1,18514}=$ 1071, $\mathrm{p}<0.001$; Fig. 3). Maximum dive depths were

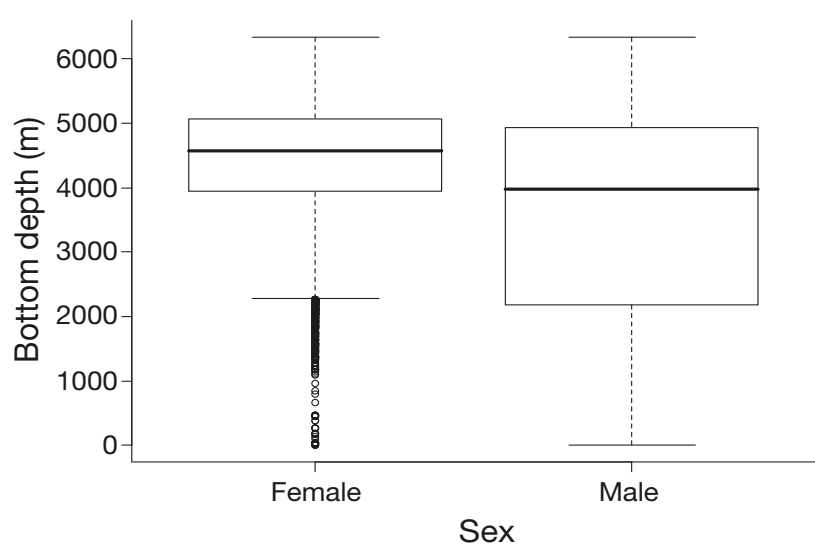

Fig. 2. Box-and-whisker plot indicating estimated water depths (Smith \& Sandwell 1997) of dive locations recorded for the selected southern elephant seal tracks in this investigation. Bold line $=$ median, box $=25$ th and 75 th percentiles, points $=$ outliers, whiskers $=1.5$ times the interquartile range, or the maximum values (when there are no outliers) 
Table 2. Summary of models with best fits. Models without an asterisk (*) are final models prior to the inclusion of an autocorrelation function. Models with an asterisk $\left({ }^{*}\right)$ indicate final models that included an autoregressive autocorrelation function. DD $=$ dive duration, $\mathrm{MD}=$ maximum dive depth, $\mathrm{ED}=$ exploited dive depth, stdl = standard length, $\mathrm{AIC}_{\mathrm{c}}=$ second order $\mathrm{AIC}$ statistic, and $\mathrm{RE}=$ random effect

\begin{tabular}{|c|c|c|c|c|}
\hline Parameter & Model & $\mathrm{AICc}$ & Significant effects & RE (\%) \\
\hline \multirow[t]{2}{*}{$\mathrm{DD}_{\mathrm{DAY}}$} & Sex + start age + stdl & 43569.4 & Stdl & 29.4 \\
\hline & Sex + start age $+\operatorname{stdl}^{*}$ & 41460.4 & Stdl & 16.5 \\
\hline \multirow[t]{2}{*}{$\mathrm{DD}_{\text {NIGHT }}$} & Sex + start age + stdl & 43522.4 & Start age + stdl & 19.2 \\
\hline & Sex + start age $+\operatorname{stdl}^{*}$ & 41835.7 & Start age + stdl & 12.9 \\
\hline \multirow[t]{2}{*}{$\mathrm{MD}_{\mathrm{DAY}}$} & Sex + start age + stdl & 35113.9 & Stdl & 43.7 \\
\hline & Sex + start age + stdl $^{*}$ & 34040.3 & Sex + stdl & 38 \\
\hline \multirow{2}{*}{$\mathrm{MD}_{\text {NIGHT }}$} & Sex + start age + stdl & 37125.6 & Sex & 16.3 \\
\hline & Sex + start age $+\operatorname{stdl}^{*}$ & 36158.8 & Sex & 11.1 \\
\hline \multirow[t]{2}{*}{$\mathrm{ED}_{\mathrm{DAY}}$} & Sex + start age + stdl & 34911.1 & Stdl & 44.4 \\
\hline & Sex + start age $+\operatorname{stdl}^{*}$ & 33880.9 & Sex + stdl & 39 \\
\hline \multirow{2}{*}{$\mathrm{ED}_{\text {NIGHT }}$} & Sex + start age + stdl & 36754.8 & Sex & 17.9 \\
\hline & Sex + start age $+\operatorname{stdl}^{*}$ & 35849.1 & Sex & 12.8 \\
\hline
\end{tabular}

rarely constrained by estimated water depths, and few evident benthic dives were observed in either sex (Fig. 4). Sex and standard length significantly affected maximum dive depths during the day, while sex was the only fixed effect influencing maximum dive depths at night in the final models (Tables 2 \& 3). Individual track (random effect) explained $38 \%$ of the variance in the final model for $\mathrm{MD}_{\mathrm{DAY}}$ and $11.1 \%$ of the variance in the final model for $\mathrm{MD}_{\mathrm{NIGHT}}$.

\section{Dive durations}

Dive durations (DD) were longer in males than females, and both sexes dived for longer mean periods of time during the day than during night-time dives $\left(\right.$ Males $_{\text {DAY }}=35.5 \pm 2.8 \mathrm{~min} ;$ Males $_{\mathrm{NIGHT}}=26.2 \pm$

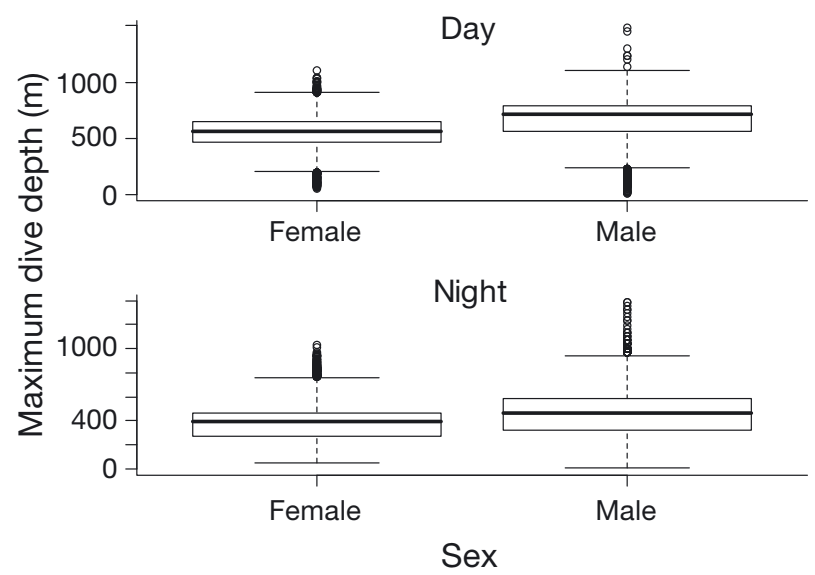

Fig. 3. Box-and-whisker plots of maximum dive depths attained by animals in the selected tracks. For definition of box plots see Fig. 2

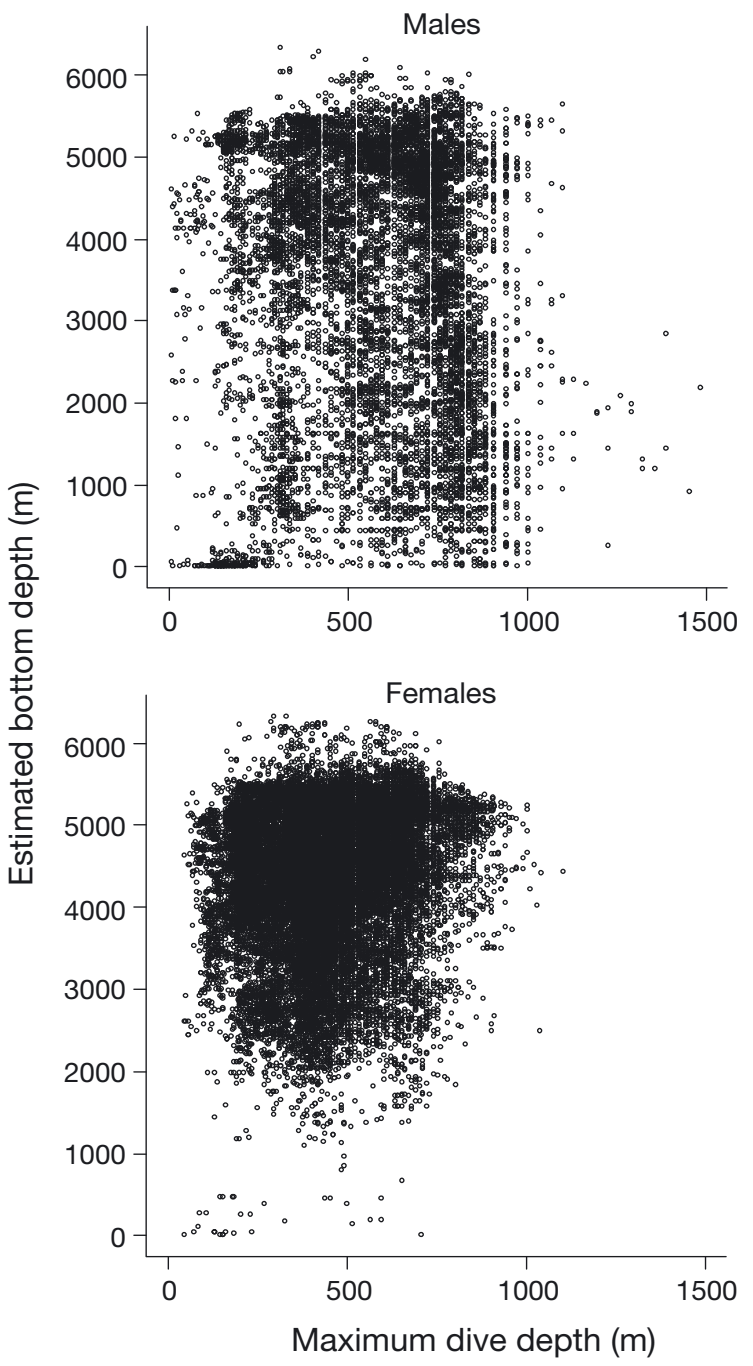

Fig. 4. Scatterplots of maximum dive depths and estimated bottom depths. Estimates of bottom depths were derived from Smith \& Sandwell (1997) 
Table 3. $F$ test results indicating significant fixed effects on final models. Boldface indicates statistically significant effects $(\mathrm{p}<0.05) . \mathrm{DD}=$ dive duration, $\mathrm{MD}=$ maximum dive depth, $\mathrm{ED}=$ exploited dive depth

\begin{tabular}{|c|c|c|c|c|}
\hline $\begin{array}{l}\text { Response } \\
\text { variable }\end{array}$ & Fixed effect & $F$ & df & $\mathrm{p}$ \\
\hline $\mathrm{DD}_{\mathrm{DAY}}$ & $\begin{array}{l}\text { Intercept } \\
\text { Sex } \\
\text { Start age } \\
\text { Stdl }\end{array}$ & $\begin{array}{c}\mathbf{9 2 4 . 1 2 4} \\
1.131 \\
0.002 \\
\mathbf{1 0 . 9 0 9}\end{array}$ & $\begin{array}{c}\mathbf{1}, \mathbf{2 7 9 0} \\
1,16 \\
1,16 \\
\mathbf{1 , 1 6}\end{array}$ & $\begin{array}{c}<\mathbf{0 . 0 0 1} \\
0.303 \\
0.969 \\
\mathbf{0 . 0 0 5}\end{array}$ \\
\hline $\mathrm{DD}_{\mathrm{NIGHT}}$ & $\begin{array}{l}\text { Intercept } \\
\text { Sex } \\
\text { Start age } \\
\text { Stdl }\end{array}$ & $\begin{array}{c}\mathbf{1 3 2 8 . 1 2 3} \\
1.761 \\
\mathbf{6 . 5 8} \\
\mathbf{9 . 9 3 3}\end{array}$ & $\begin{array}{c}\mathbf{1}, \mathbf{2 9 0 4} \\
1,16 \\
\mathbf{1}, 16 \\
\mathbf{1 . 1 6}\end{array}$ & $\begin{array}{c}<\mathbf{0 . 0 0 1} \\
0.203 \\
\mathbf{0 . 0 2 1} \\
\mathbf{0 . 0 0 6}\end{array}$ \\
\hline $\mathrm{MD}_{\mathrm{DAY}}$ & $\begin{array}{l}\text { Intercept } \\
\text { Sex } \\
\text { Start age } \\
\text { Stdl }\end{array}$ & $\begin{array}{c}\mathbf{6 5 1 . 9 3 2} \\
\mathbf{4 . 7 6 2} \\
0.018 \\
\mathbf{4 . 7 5 2}\end{array}$ & $\begin{array}{c}\mathbf{1}, \mathbf{2 7 9 0} \\
\mathbf{1}, 16 \\
1,16 \\
\mathbf{1}, 16\end{array}$ & $\begin{array}{c}<\mathbf{0 . 0 0 1} \\
\mathbf{0 . 0 4 4} \\
0.894 \\
\mathbf{0 . 0 4 5}\end{array}$ \\
\hline $\mathrm{MD}_{\mathrm{NIGHT}}$ & $\begin{array}{l}\text { Intercept } \\
\text { Sex } \\
\text { Start age } \\
\text { Stdl }\end{array}$ & $\begin{array}{c}\mathbf{1 1 6 2 . 9 6 1} \\
\mathbf{1 3 . 6 0 9} \\
1.028 \\
0.234\end{array}$ & $\begin{array}{c}\mathbf{1}, \mathbf{2 9 0 4} \\
\mathbf{1}, \mathbf{1 6} \\
1,16 \\
1,16\end{array}$ & $\begin{array}{c}<\mathbf{0 . 0 0 1} \\
\mathbf{0 . 0 0 2} \\
0.326 \\
0.635\end{array}$ \\
\hline $\mathrm{ED}_{\mathrm{DAY}}$ & $\begin{array}{l}\text { Intercept } \\
\text { Sex } \\
\text { Start age } \\
\text { Stdl }\end{array}$ & $\begin{array}{c}\mathbf{5 8 7 . 4 1 6} \\
\mathbf{4 . 5 0 2} \\
0.006 \\
\mathbf{5 . 3 7 4}\end{array}$ & $\begin{array}{c}\mathbf{1}, \mathbf{2 7 9 0} \\
\mathbf{1}, \mathbf{1 6} \\
1,16 \\
\mathbf{1}, 16\end{array}$ & $\begin{array}{c}<\mathbf{0 . 0 0 1} \\
\mathbf{0 . 0 5} \\
0.939 \\
\mathbf{0 . 0 3 4}\end{array}$ \\
\hline $\mathrm{ED}_{\mathrm{NIGHT}}$ & $\begin{array}{l}\text { Intercept } \\
\text { Sex } \\
\text { Start age } \\
\text { Stdl }\end{array}$ & $\begin{array}{c}\mathbf{9 3 1 . 2 5} \\
\mathbf{1 0 . 5 7 2} \\
1.189 \\
0.267\end{array}$ & $\begin{array}{c}\mathbf{1}, \mathbf{2 9 0 4} \\
\mathbf{1 , 1 6} \\
1,16 \\
1,16\end{array}$ & $\begin{array}{c}<\mathbf{0 . 0 0 1} \\
\mathbf{0 . 0 0 5} \\
0.292 \\
0.612\end{array}$ \\
\hline
\end{tabular}

9.5 min; Females ${ }_{\mathrm{DAY}}=31.8 \pm 9.7$ min; Females $_{\mathrm{NIGHT}}=$ $24 \pm 7.4 \mathrm{~min}$ ) (Fig. 5). The best model for $\mathrm{DD}_{\mathrm{DAY}}$ indicated that standard length was the only significant fixed effect influencing this parameter (Table 3). A weak, but statistically significant positive correlation existed between $\mathrm{DD}_{\mathrm{DAY}}$ and standard length (Pearson: $\mathrm{r}=0.31, \mathrm{df}=2808, \mathrm{p}<0.001)$. Both standard length and start age were identified as significantly influencing $\mathrm{DD}_{\mathrm{NIGHT}}$. Individual track (random effect) explained $16.5 \%$ and $12.9 \%$ of the variance in the final models for $\mathrm{DD}_{\mathrm{DAY}}$ and $\mathrm{DD}_{\mathrm{NIGHT}}$ respectively.

\section{Exploited dive depths}

Exploited dive depths were deeper in males than in females, and deeper during daytime dives when compared to night-time dives for both sexes $\left(\right.$ Males $_{\mathrm{DAY}}=$ $622.2 \pm 185.8 \mathrm{~m} ;$ Males $_{\mathrm{NIGHT}}=416.6 \pm 186.4 \mathrm{~m}$; Females $_{\mathrm{DAY}}=511.2 \pm 134.1 \mathrm{~m}$; Females $_{\mathrm{NIGHT}}=342.5 \pm$ $136.6 \mathrm{~m})$. Males displayed more variation in exploited dive depths than females $\left(\mathrm{ANOVA}_{\mathrm{DAY}}: F_{1,17230}=\right.$ 2020.8, p < 0.001; ANOVA NIGHT $_{1} F_{1,18514}=892.77, \mathrm{p}<$ 0.001; Fig. 6). Best models for exploited depth indi-

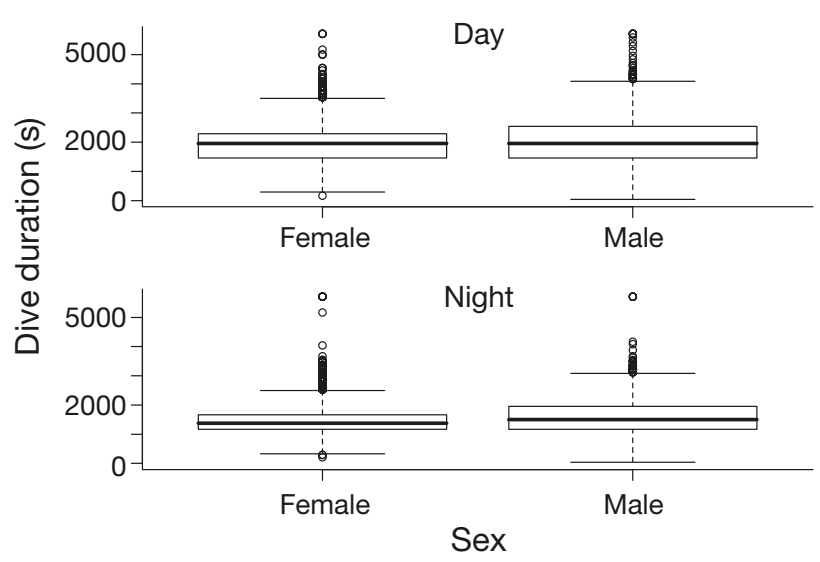

Fig. 5. Box-and-whisker plots of dive durations recorded for the southern elephant seal tracks selected for this investigation. For definition of box plots see Fig. 2

cated that sex and standard length significantly influenced exploited dive depths during daytime dives (Table 3). Sex was identified as the only fixed effect significantly influencing exploited depths at night. Individual track (random effect) explained $38.9 \%$ of the variance in the final model for $\mathrm{ED}_{\mathrm{DAY}}$ and $12.8 \%$ of the variance in the final model for $\mathrm{ED}_{\mathrm{NIGHT}}$.

\section{DISCUSSION}

This study investigated the effects of sex, size and age on a number of dive parameters measured in southern elephant seals from Marion Island. By examining track and dive data obtained from seals from a range of sizes (standard lengths) in each sex, we were able to elucidate the influence of such effects using a mixed-effects modelling approach.

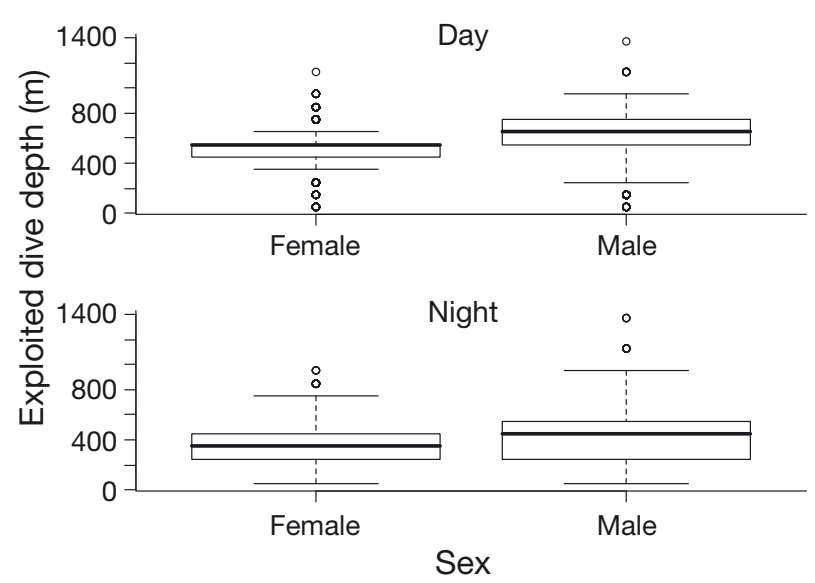

Fig. 6. Box-and-whisker plots of exploited dive depths of southern elephant seal tracks selected for this study. For definition of box plots see Fig. 2 


\section{Sex versus size}

Males in our sample undertook longer and deeper foraging dives than females - dives characterised by increases in time spent at the bottom of dives. Male southern elephant seals displayed more variation in maximum and exploited dive depths than females (Figs. 3 \& 6). Sex was considered a significant effect in final models for maximum dive depth and exploited dive depth during day- and night-time. However, sex did not have a significant effect in final models for dive duration. Standard length was incorporated in the best models for all dive parameters. It was identified as being a statistically significant effect for dive durations during day- and night-times, as well as maximum and exploited dive depths during daytime. While the inclusion of standard length improved all final models, it was not identified as a significant effect for maximum or exploited depths at night.

These results suggest that differences observed in dive durations between sexes are likely to be due largely to increased physiological capability associated with different body sizes. Swim speed and body mass have previously been reported to be positively correlated with dive durations in female southern elephant seals from Macquarie Island (Hindell et al. 2000). Similarly, a positive relationship between body mass and dive durations was reported for underyearling southern elephant seals from the same population (Irvine et al. 2000).

However, body size (standard length) did not appear to drive differences observed between sexes in maximum and exploited dive depths. While sex significantly influenced both these parameters for daytime dives, it was identified as consistently affecting maximum and exploited dive depths during day- and nighttime dives. This suggests that male and female southern elephant seals target different depth layers and their associated resources owing to differences in foraging strategy, and that dive depths are not merely a by-product of body size and their associated physiological capacity.

We used standard length as a proxy measurement for body size. While such a measurement was not sufficient to estimate body condition in the study animals, it was considered likely to provide an overall indication of physiological capability over an extended timescale. Body condition in southern elephant seals is known to vary substantially during their foraging migrations and over seasonal timescales (Bennet et al. 2001, Biuw et al. 2007). Such changes in body condition can be expected to directly influence dive performance owing to changes in buoyancy associated with blubber gain and loss. Other seasonal influences on dive performance have been suggested, including reproductive condition of females, seasonal fluctuations in basal metabolic rate, seasonal alterations in oxygen affinity of haemoglobin and myoglobin, increases in muscle oxygen storage capacity, increases in physical fitness, and seasonal changes in prey type (Bennet et al. 2001). Such factors are likely to have resulted in the large variances in dive parameters reported here and require further investigation. Furthermore, differences in metabolic requirements between males and females of similar ages (nonbreeding males provisioning for growth and females for breeding) (Field et al. 2005a) were likely to have resulted in different body conditions and dive performance between sexes.

\section{Influence of age}

Dietary shifts associated with age have previously been described for juvenile and sub-adult southern elephant seals (Field et al. 2007b, Bailleul et al. 2010). We therefore expected age to exhibit significant influences on maximum and exploited dive depths. Surprisingly, age was only identified as being a statistically significant fixed effect in one of the models selected $\left(\mathrm{DD}_{\mathrm{NIGHT}}\right)$, though it was always included as a contributing effect in the model structures. Since we selected the sample of animals to obtain a sufficient overlap in standard lengths between sexes, the study was limited to individuals of ages between 2 yr 6 mo and 8 yr 4 mo. We therefore did not include any dive data from underyearlings or yearlings - ages at which dietary changes associated with increased dive capacity would perhaps be most evident. Indeed, stable isotope ratios indicate that young males from the Kerguelen Islands show an increase in foraging trophic level from approximately 3 to $4 \mathrm{yr}$ of age (Bailleul et al. 2010). The exclusion of very young and older adult animals (this study) probably also resulted in the lack of correlation between age and standard length in our study sample.

\section{Individual variation in dive behaviour}

Individual variation explained large proportions of the total variance in many of the final models selected in this study (11.1 to $39 \%$ ). The influence of individual variation declined in all models after inclusion of the autoregressive correlation functions. Individual track variation explained more of the model variance for all daytime dive behaviour models than for night-time models. Slight increases in variation were evident in most night-time dive behaviour parameters, when compared to daytime dive behaviour (Figs. 3, 5 \& 6), though this variation did not appear sufficient to clarify 
the differences in variance explained by individual tracks between day- and night-time dives.

Individual variation potentially plays a significant role in the behaviour of various animal taxa (Bolnick et al. 2003) and has previously been reported in dive behaviour of southern elephant seals (Field et al. 2001) and other pinnipeds (Staniland et al. 2004, Chilvers \& Wilkinson 2009, Kuhn et al. 2009). Individual variation has often been ascribed to the influence of dive localities and the associated bathymetry and prey distribution on an individual's behaviour. Our results did not provide support for any particular explanation for the influence of individual variation in our sample. However, while we acknowledge the likely influence of localised conditions and prey distribution on the dive behaviour of individuals, some differences in individual strategy appear to be evident (T. McIntyre unpubl. data).

The smaller amount of variation explained by the effect of individual for night-time dive parameters suggests that southern elephant seals perhaps use less specialised strategies for night-time foraging purposes. This, in turn, could be the result of prey resources displaying less patchy distributions at night and concentrating their activity in shallower water layers (Collins \& Rodhouse 2006, Collins et al. 2008).

\section{Diel variation and diet}

Southern elephant seals prey largely on squid and myctophid fishes (Bradshaw et al. 2003, van den Hoff et al. 2003), though substantial inter-population and seasonal differences in diet have been documented (Bradshaw et al. 2003, Cherel et al. 2008). Comparatively little is known about the diet of southern elephant seals hauled out at Marion Island. Diel variation in all dive parameters measured was evident in the sample of tracks investigated. Males and females dive to deeper depths for longer periods of time during daytime dives than during night-time dives (Figs. 3, 5 \& 6). Such variation suggests that both male and female southern elephant seals target vertically migrating, pelagic prey species (Hindell et al. 1991, Jonker \& Bester 1994, Bost et al. 2002), though males evidently target prey occurring at deeper depths than do females (Fig. 3). Dive depths were rarely constrained by estimated bottom depths, and few benthic dives were recorded in our sample. This is not surprising, given the deep water immediately surrounding Marion Island, and that seals from this population evidently do not often target large areas of shallow bathymetry (e.g. continental shelves). Our results differ from those reported for other populations, notably Peninsula Valdés (Campagna et al. 1999), Kerguelen Islands (Bailleul et al. 2007, Bailleul et al. 2010) and Macquarie
Island (Hindell et al. 1991), where males often forage benthically over continental and oceanic shelves. The different foraging strategy reported here for males from Marion Island highlights the evident foraging plasticity between populations of this species.

\section{Resource selection and partitioning}

The avoidance of intra-specific competition between sexes, as well as age-classes, has previously been proposed to drive resource partitioning in southern elephant seals (Lewis et al. 2006, Field et al. 2007a, Newland et al. 2009). While elephant seals from other populations segregate spatially between the sexes (Slip et al. 1994, Campagna et al. 1995, Campagna et al. 1999, Bornemann et al. 2000, Tosh et al. 2009, Bailleul et al. 2010), animals from Marion Island appear to largely segregate between the sexes by targeting different water depths in oceanic habitats.

Our results suggest that both sex and body length play important roles in the dive behaviour of southern elephant seals from Marion Island. Segregation between the sexes was evident in the vertical depth layers targeted by animals of either sex - males diving deeper than females and also evidently exploiting increased depths. The dive depths obtained and targeted by animals were evidently not constrained by physiological capacity (associated with body size), but rather selected by the individual animals. This provides support for a hypothesis that segregation in dive depths of southern elephant seals is largely driven by forage selection and an associated avoidance of intraspecific competition.

The comparative lack of influence that sex exhibited on dive durations in this investigation further indicated that the physical size of animals did not govern the depths utilised, but rather the amount of time seals were able to spend at targeted depths. This result supports previous investigations that highlighted a positive correlation between body size and maximum dive durations (Hindell et al. 2000, Irvine et al. 2000).

\section{CONCLUSION}

We presented results from mixed-effects models to elucidate the effects of sex, age and size on the dive behaviour of a highly sexually dimorphic mammal, the southern elephant seal. While individual variation accounted for substantial portions of variance in the models, differences in maximum and targeted depths were always influenced by sex and only partly influenced by body length. Conversely, dive durations were always influenced by body length, while sex was not 
identified as a significant influence. These results support previous investigations in which physiological capability associated with size was hypothesised as being a limiting factor on dive durations (Hindell et al. 2000, Irvine et al. 2000). However, our results suggest that sexual segregation in vertical depth use (i.e. maximum and exploited dive depths) by southern elephant seals is largely a result of forage selection and not a result of size differences between sexes. This provides support for resource partitioning between sexes and the potential avoidance of intra-specific competition in this species (Field et al. 2007a). Furthermore, interpopulation differences in sexual segregation (i.e. by using different water depths in pelagic habitats or by utilising different spatial foraging habitats) highlight the plasticity in forage strategies of southern elephant seal populations.

Acknowledgements. We thank Nico de Bruyn, Chris Oosthuizen, Mashudu Phalanndwa, Ryan Reisinger, Thomas Mufanadzo, Phathu Radzilani, Brent Stewart and Greg Hofmeyr for assistance with deployments of satellite tags in the field. Nils Bunnefeld provided fruitful discussion on the use of mixed-effects models, and Nico de Bruyn and Nils Bunnefeld provided useful comments on a previous version of this manuscript. Christophe Guinet and 3 anonymous reviewers provided constructive criticism that greatly improved this manuscript. We are further grateful to the Alfred Wegener Institute for Polar and Marine Research (Germany), the Department of Science and Technology through the National Research Foundation (South Africa) and the South African National Antarctic Programme for financial and logistical support.

\section{LITERATURE CITED}

Argos (1996) Argos User's Manual. Collecte Localisation Satellites (CLS)

Bailleul F, Charrassin JB, Ezraty R, Girard-Ardhuin F, McMahon CR, Field IC, Guinet C (2007) Southern elephant seals from Kerguelen Islands confronted by Antarctic Sea ice. Changes in movements and in diving behaviour. DeepSea Res II 54:343-355

Bailleul F, Pinaud D, Hindell M, Charrassin JB, Guinet C (2008) Assessment of scale-dependent foraging behaviour in southern elephant seals incorporating the vertical dimension: a development of the First Passage Time method. J Anim Ecol 77:948-957

Bailleul F, Authier M, Ducatez S, Roquet F, Charrassin JB, Cherel Y, Guinet C (2010) Looking at the unseen: combining animal bio-logging and stable isotopes to reveal a shift in the ecological niche of a deep diving predator. Ecography doi:10.1111/j.1600-0587.2009.06034.x

Bajzak CE, Côté SD, Hammill MO, Stenson G (2009) Intersexual differences in the postbreeding foraging behaviour of the Northwest Atlantic hooded seal. Mar Ecol Prog Ser 385:285-294

Bennett KA, McConnell BJ, Fedak MA (2001) Diurnal and seasonal variations in the duration and depth of the longest dives in southern elephant seals (Mirounga leonina): possible physiological and behavioural constraints. J Exp Biol 204:649-662
Bester MN (1988) Marking and monitoring studies of the Kerguelen stock of southern elephant seals Mirounga leonina and their bearing on biological research in the Vestfold Hills. Hydrobiologia 165:269-277

Biuw M, Boehme L, Guinet C, Hindell MA and others (2007) Variations in behavior and condition of a Southern Ocean top predator in relation to in situ oceanographic conditions. Proc Natl Acad Sci USA 104:13705-13710

Boehme L, Lovell P, Biuw M, Roquet F and others (2009) Technical Note: Animal-borne CTD-Satellite Relay Data Loggers for real-time oceanographic data collection. Ocean Sci 5:685-695

- Bolker BM, Brooks ME, Clark CJ, Geange SW, Poulsen JR, Stevens HH, White JSS (2009) Generalized linear mixed models: a practical guide for ecology and evolution. Trends Ecol Evol 24:127-135

Bolnick DI, Svanbäck R, Fordyce JA, Yang LH, Davis JM, Hulsey CD, Forister ML (2003) The ecology of individuals: incidence and implications of individual specialization. Am Nat 161:1-28

> Börger L, Franconi N, Ferretti F, Meschi F, De Michele G, Gantz A, Coulson T (2006) An integrated approach to identify spatiotemporal and individual-level determinants of animal home range sizes. Am Nat 168:471-485

> Bornemann H, Kreyscher M, Ramdohr S, Martin T, Carlini AR, Sellmann L, Plötz J (2000) Southern elephant seal movements and Antarctic sea ice. Antarct Sci 12:3-15

Bost CA, Zorn T, Le Maho Y, Dulhamel G (2002) Feeding of diving predators and diel vertical migration of prey: King penguins' diet versus trawl sampling at Kerguelen Islands. Mar Ecol Prog Ser 227:51-61

> Bradshaw CJA, Hindell MA, Best NJ, Philip KL, Wilson G, Nichols PD (2003) You are what you eat: describing the foraging ecology of southern elephant seals (Mirounga leonina) using blubber fatty acids. Proc R Soc Lond B Biol Sci 270:1283-1292

Breed GA, Bowen WD, McMillan JI, Leonard ML (2006) Sexual segregation of seasonal foraging habitats in a nonmigratory marine mammal. Proc R Soc Lond B Biol Sci 273:2319-2326

> Bunnefeld N, Newborn D, Milner-Gulland EJ (2009) Factors affecting unintentional harvesting selectivity in a monomorphic species. J Anim Ecol 78:485-492

Burnham KP, Anderson DR (2002) Model selection and multimodel inference: a practical information-theoretic approach. Springer Science + Business Media, New York, NY

Burns JM, Hindell MA, Bradshaw CJA, Costa DP (2008) Finescale habitat selection of crabeater seals as determined by diving behavior. Deep-Sea Res II 55:500-514

Campagna C, Le Boeuf BJ, Blackwell SB, Crocker DE, Quintana F (1995) Diving behaviour and foraging location of female southern elephant seals from Patagonia. J Zool 236:55-71

Campagna C, Fedak M, McConnell BJ (1999) Post-breeding distribution and diving behavior of adult male southern elephant seals from Patagonia. J Mammal 80:1341-1352

> Cherel Y, Ducatez S, Fontaine C, Richard P, Guinet C (2008) Stable isotopes reveal the trophic position and mesopelagic fish diet of female southern elephant seals breeding on the Kerguelen Islands. Mar Ecol Prog Ser 370: 239-247

Chilvers BL, Wilkinson IS (2009) Diverse foraging strategies in lactating New Zealand sea lions. Mar Ecol Prog Ser 378: 299-308

Ciuti S, Apollonio M (2008) Ecological sexual segregation in fallow deer (Dama dama): a multispatial and multitemporal approach. Behav Ecol Sociobiol 62:1747-1759 
Collins MA, Rodhouse PGK (2006) Southern Ocean cephalopods. Adv Mar Biol 50: 191-265

Collins MA, Xavier JC, Johnston NM, North AW and others (2008) Patterns in the distribution of myctophid fish in the northern Scotia Sea ecosystem. Polar Biol 31:837-851

Crawley MJ (2007) The R book. John Wiley \& Sons Ltd, Chichester

de Bruyn PJN, Tosh CA, Oosthuizen WC, Phalanndwa MV, Bester MN (2008) Temporary marking of unweaned southern elephant seal (Mirounga leonina L.) pups. S Afr J Wildl Res 38:133-137

ESRI (1998) Arc and grid command references. Environmental Systems Research Institute, Redlands, CA

> Fedak M, Lovell P, Grant SM (2001) Two approaches to compressing and interpreting time-depth information and satellite-linked data recorders as collected by time-depth recorders. Mar Mamm Sci 17:94-110

Field I, Hindell MA, Slip D, Michael KJ (2001) Foraging strategies of southern elephant seals (Mirounga leonina) in relation to frontal zones and water masses. Antarct Sci 13:371-379

Field IC, Bradshaw CJA, Burton HR, Hindell MA (2005a) Juvenile southern elephant seals exhibit seasonal differences in energetic requirements and use of lipids and protein stores. Physiol Biochem Zool 78:491-504

Field IC, Bradshaw CJA, Burton HR, Sumner MD, Hindell MA (2005b) Resource partitioning through oceanic segregation of foraging juvenile southern elephant seals (Mirounga leonina). Oecologia 142:127-135

Field IC, Bradshaw CJA, Burton HR, Hindell MA (2007a) Differential resource allocation strategies in juvenile elephant seals in the highly seasonal Southern Ocean. Mar Ecol Prog Ser 331:281-290

Field IC, Bradshaw CJA, Van den Hoff J, Burton HR, Hindell MA (2007b) Age-related shifts in the diet composition of southern elephant seals expand overall foraging niche. Mar Biol 150:1441-1452

Ford NB, Hampton PM (2009) Ontogenetic and sexual differences in diet in an actively foraging snake, Thamnophis proximus. Can J Zool 87:254-261

> González-Solís J, Croxall JP, Afanasyev V (2008) Offshore spatial segregation in giant petrels Macronectes spp.: differences between species, sexes and seasons. Aquat Conserv 17:S22-S36

> Hay CT, Cross PC, Funston PJ (2008) Trade-offs of predation and foraging explain sexual segregation in African buffalo. J Anim Ecol 77:850-858

> Hindell MA, Slip DJ, Burton HR (1991) The diving behaviour of adult male and female southern elephant seals, Mirounga leonina (Pinnipedia: Phocidae). Aust J Zool 39: 595-619

> Hindell MA, Lea MA, Morrice MG, McMahon CR (2000) Metabolic limits on dive duration and swimming speed in the southern elephant seal Mirounga leonina. Physiol Biochem Zool 73:790-798

Hoodge PN, Eichenlaub B (1997) Animal movement extension for Arcview. ver. 1.1. Alaska Science Center - Biological Science Office, U.S. Geological Survey, Anchorage, AK, USA

Irvine LG, Hindell MA, van den Hoff J, Burton HR (2000) The influence of body size on dive duration of underyearling southern elephant seals (Mirounga leonina). J Zool 251: 463-471

Jonker FC (1997) Ranging and diving behaviour of adult female southern elephant seals from Marion Island. MSc dissertation, University of Pretoria

Jonker FC, Bester MN (1994) The diving behaviour of adult southern elephant seal, Mirounga leonina, cows from
Marion Island. S Afr J Antarct Res 24:75-93

$>$ Kuhn CE, Crocker DE, Tremblay Y, Costa DP (2009) Time to eat: measurements of feeding behaviour in a large marine predator, the northern elephant seal Mirounga angustirostris. J Anim Ecol 78:513-523

Le Boeuf BJ, Laws RM (1994) Elephant seals: population ecology, behavior, and physiology. University of California Press, Berkeley

Lesage V, Hammill MO, Kovacs KM (1999) Functional classification of harbor seal (Phoca vitulina) dives using depth profiles, swimming velocity, and an index of foraging success. Can J Zool 77:74-87

> Lewis R, O'Connell T, Lewis M, Campagna C, Hoelzel AR (2006) Sex-specific foraging strategies and resource partitioning in the southern elephant seal (Mirounga leonina). Proc R Soc Lond B Biol Sci 273:2901-2907

Li Z, Jiang Z (2008) Sexual segregation in Tibetan gazelle: a test of the activity budget hypothesis. J Zool 274:327-331

- MacFarlane AM, Coulson G (2007) Sexual segregation in western grey kangaroos: testing alternative evolutionary hypotheses. J Zool 273:220-228

Malherbe J (1998) The diving and ranging behaviour of southern elephant seal, Mirounga leonina, bulls. MSc dissertation, University of Pretoria

> Martin AR, da Silva VMF (2004) River dolphins and flooded forest: seasonal habitat use and sexual segregation of botos (Inia geoffrensis) in an extreme cetacean environment. J Zool 263:295-305

> McConnell BJ, Fedak M (1996) Movements of southern elephant seals. Can J Zool 74:1485-1496

McConnell BJ, Chambers C, Fedak MA (1992) Foraging ecology of southern elephant seals in relation to the bathymetry and productivity of the Southern Ocean. Antarct Sci 4:393-398

McIntyre T, de Bruyn PJN, Ansorge IJ, Bester MN, Bornemann H, Plötz J, Tosh CA (2010) A lifetime at depth: vertical distribution of southern elephant seals in the water column. Polar Biol 33:1037-1048

> Morales MB, Traba J, Carriles E, Delgado MP, de la Morena ELG (2008) Sexual differences in microhabitat selection of breeding little bustards Tetrax tetrax: ecological segregation based on vegetation structure. Acta Oecol 34:345-353

> Mucientes GR, Queiroz N, Sousa LL, Tarroso P, Sims DW (2009) Sexual segregation of pelagic sharks and the potential threat from fisheries. Biol Lett 5:156-159

> Newland C, Field IC, Nichols PD, Bradshaw CJA, Hindell MA (2009) Blubber fatty acid profiles indicate dietary resource partitioning between adult and juvenile southern elephant seals. Mar Ecol Prog Ser 384:303-312

> Page B, McKenzie J, Goldsworthy SD (2005) Inter-sexual differences in New Zealand fur seal diving behaviour. Mar Ecol Prog Ser 304:249-264

Palacin C, Alonso JC, Alonso JA, Martin CA, Magan M, Martin B (2009) Differential migration by sex in the great bustard: possible consequences of an extreme sexual size dimorphism. Ethology 115:617-626

Pinheiro JC, Bates DM (2004) Mixed-effects models in S and S-Plus. Springer, New York, NY

R Development Core Team (2008) R: a language and environment for statistical computing. R Foundation for Statistical Computing, Vienna, Austria 3-900051-07-0 www.R-project.org

Ruckstuhl KE (2007) Sexual segregation in vertebrates: proximate and ultimate causes. Integr Comp Biol 47:245-257

Schreer JF, Kovacs KM, O'Hara Hines RJ (2001) Comparative diving patterns of pinnipeds and seabirds. Ecol Monogr 71:137-162 
Shannon G, Page BR, Mackey RL, Duffy KJ, Slotow R (2008) Activity budgets and sexual segregation in African elephants (Loxodonta africana). J Mammal 89:467-476

Slip DJ, Hindell MA, Burton HR (1994) Diving behavior of southern elephant seals from Macquarie Island: an overview. In: Le Boeuf BJ, Laws RM (eds) Elephant seals: population ecology, behavior, and physiology. University of California Press, Berkeley, p 253-270

Smith WHF, Sandwell DT (1997) Global sea floor topography from satellite altimetry and ship depth soundings. Science 277:1956-1962

Staniland IJ, Robinson SL (2008) Segregation between the sexes: Antarctic fur seals, Arctocephalus gazella, foraging at South Georgia. Anim Behav 75:1581-1590

Staniland IJ, Reid K, Boyd IL (2004) Comparing individual and spatial influences on foraging behaviour in Antarctic fur seals Arctocephalus gazella. Mar Ecol Prog Ser 275: 263-274

Tosh CA, Bornemann H, Ramdohr S, Schröder M and others (2009) Adult male southern elephant seals from King George Island utilize the Weddell Sea. Antarct Sci 21:

Editorial responsibility: Rory Wilson,

Swansea, UK

\section{$113-121$}

van den Hoff J, Burton HR, Davies R (2003) Diet of male southern elephant seals (Mirounga leonina L.) hauled out at Vincennes Bay, East Antarctica. Polar Biol 26: $27-31$

> Vincent C, McConnell BJ, Ridoux V, Fedak MA (2002) Assessment of Argos location accuracy from satellite tags deployed on captive gray seals. Mar Mamm Sci 18: 156-166

Wearmouth VJ, Sims DW (2008) Sexual segregation in marine fish, reptiles, birds and mammals: behaviour patterns, mechanisms and conservation implications. Adv Mar Biol 54:107-170

Whitehead H, Weilgart L (2000) The sperm whale: social females and roving males. In: Mann J, Connor RC, Tyack PL, Whitehead H (eds) Cetacean societies: field studies of dolphins and whales. The University of Chicago Press, Chicago, IL, p 154-172

> Wolf JBW, Kauermann G, Trillmich F (2005) Males in the shade: habitat use and sexual segregation in the Galápagos sea lion (Zalophus californianus wollebaeki). Behav Ecol Sociobiol 59:293-302

Submitted: November 11, 2009; Accepted: May 28, 2010

Proofs received from author(s): July 26, 2010 